\title{
Aspectos epidemiológicos da queima das pontas das folhas da cebola na região do Alto Vale do Itajái em Santa Catarina
}

\author{
Leandro Luiz Marcuzzo ${ }^{1}$, Bruna Kotkoski² ${ }^{\circledR}$, Cristiane Wernke ${ }^{2} \odot$
}

${ }^{1}$ Instituto Federal Catarinense - IFC/Campus Rio do Sul, Estrada do redentor 5665, Bairro canta Galo, CP 441, CEP 89163-356, Rio do Sul-SC, Brasil. ${ }^{2}$ Aluna do curso de agronomia IFC/Campus Rio do Sul, Bolsista PIBITI e PIBIC/Cnpq, Instituto Federal Catarinense - IFC/Campus Rio do Sul, Estrada do redentor 5665, Bairro canta Galo, CP 441, CEP 89163-356, Rio do Sul-SC, Brasil.

Autor para correspondência: Leandro Luiz Marcuzzo (leandro.marcuzzo@ifc.edu.br)

Data de chegada: 06/07/2018. Aceito para publicação em: 01/04/2020.

$10.1590 / 0100-5405 / 206952$

\section{RESUMO}

Marcuzzo, L.L.; Kotkoski, B.; Wernke, C. Nascimento, A. Aspectos epidemiológicos da queima das pontas das folhas da cebola na região do Alto Vale do Itajaí em Santa Catarina. Summa Phytopathologica, v.46, n.2, p.135-139, 2020.

Com objetivo de estudar a epidemiologia da queima das pontas das folhas da cebola causada por Botrytis squamosa na região do alto vale do Itajaí/SC, um ensaio foi conduzido com plantas naturalmente infectadas, nas safras 2017 e 2018. A cada sete dias e, durante 10 semanas, foi quantificada a população de conídios no ar, registrada as condições ambientais e avaliada a severidade nas plantas. Observou-se, que mesmo com ambiente favorável à doença, seu início ocorreu cinco semanas após a semeadura. Constatou-se que a epidemia iniciou uma semana depois da primeira detecção do inóculo no ar em 2018. O progresso da doença foi representado pelo modelo de Gompertz $\mathrm{y}=0,51830 *(\exp (-5,95660 * \exp (-0,47392 * x)))$. A produção da biomassa fresca de mudas foi de 1,68 e 2,8 gramas por planta nos respectivos anos de avaliação. Este estudo epidemiológico pode fornecer informações do momento do início da epidemia e será útil na validação de um sistema de previsão da queima das pontas das folhas da cebola.

Palavras-chave: Allium cepa, epidemiologia, Botrystis squamosa.

\section{ABSTRACT}

Marcuzzo, L.L.; Kotkoski, B.; Wernke, C. Epidemiological aspects of Botrytis leaf blight in the region of "Alto Vale do Itajaí", Santa Catarina State, Brazil. Summa Phytopathologica, v.46, n.2, p.135-139, 2020.

With the aim of studying the epidemiology of Botrytis leaf blight, caused by Botrytis squamosa in the region of Alto Vale do Itajaí, Santa Catarina State, Brazil, an assay was conducted with naturally infected plants in 2017 and 2018 growing seasons. Every seven days, for 10 weeks, the population of conidia in the air was quantified, the environmental conditions were recorded and the severity in plants was evaluated. Even in an environment favorable to the disease, its onset occurred five weeks after sowing. The epidemic started one week after the first detection of inoculum in the air in 2018. The disease progress was represented by the Gompertz model $\mathrm{y}=0.51830 *(\exp (-5.95660 * \exp (-0.47392 * \mathrm{x})))$. Fresh biomass production of seedlings was 1.68 and 2.8 grams per plant in the respective evaluation years. This epidemiological study can provide information about the beginning of the epidemic and will be useful in the validation of a forecasting system for Botrytis leaf blight in onion.

Keywords: Allium cepa, epidemiology, Botrytis squamosa.

A cultura da cebola (Allium cepa L.) ocupa o terceiro lugar entre as hortaliças de expressão econômica do Brasil e constitui atividade socioeconômica de relevante para pequenos agricultores da região sul. $\mathrm{O}$ Estado de Santa Catarina possui a maior área de cultivo da cebola e, na safra de 2017, a produção atingiu 509.389 toneladas (8) representando $29,6 \%$ do total produzido do país, sendo que $75 \%$ está concentrada na região do Alto Vale do Itajaí (17).

$\mathrm{Na}$ cultura da cebola, diversos são os fatores que contribuem para a baixa produtividade da cultura, e dentre estes, estão as doenças de diversas etiologias, que causam danos à cultura. Entre estas, a queima das pontas das folhas da cebola causada por Botrytis squamosa Walker é uma doença de importância econômica na produção de mudas na região do alto vale do Itajaí, já que mais de $80 \%$ da área plantada vem do transplantio de mudas em decorrência do relevo acentuado que inviabiliza a semeadura direta com máquinas. $\mathrm{Na}$ época de cultivo das mudas que dura em torno de 60 a 80 dias ocorrem condições de temperaturas amenas (abaixo de $22^{\circ} \mathrm{C}$ ) e alta ( $\geq 90 \%$ ) umidade relativa do ar e a doença incide em toda a parte aérea da planta resultando na redução da produtividade e qualidade da muda a ser transplantada (2, 18, 26).

No estudo de epidemias, a dinâmica temporal das doenças de plantas tem sido enfatizada, pois o progresso de doenças é frequentemente é facilmente visualizada (9). Para estabelecer relações entre o progresso de uma epidemia é necessário conhecer as condições ambientais favoráveis para o desenvolvimento do patógeno (22). Trabalhos envolvendo acompanhamento epidemiológico têm como objetivo constatar períodos da cultura em que ocorre maior intensidade da doença (3), onde o monitoramento da flutuação da população de esporos no ar também é utilizado para avaliar a dinâmica do progresso da doença $(19,20)$.

Para o caso da queima das pontas das folhas da cebola, dentre os aspectos epidemiológicos, desconhece-se o comportamento da doença 
nas condições de campo quanto ao início e o progresso de epidemia e, portanto, este trabalho pretendeu estudar a epidemiologia da queima das pontas das folhas da cebola causada por Botrytis squamosa na região do alto vale do Itajaí/SC.

\section{MATERIAL E MÉTODOS}

O estudo epidemiológico da queima das pontas das folhas da cebola foi conduzido no Instituto Federal Catarinense - IFC/Campus Rio do Sul, no município de Rio do Sul - SC, (Latitude: 27¹1'07' S e Longitude: 49³9'39' W, altitude 655 metros acima do nível do mar) durante o período de 17 de abril a 30 de junho de 2017 e de 16 de abril a 29 de junho de 2018 totalizando 10 semanas após a semeadura.

O registro das variáveis meteorológicas como temperatura, umidade relativa e precipitação pluvial foram obtidos em uma estação meteorológica (Davis vantage vue ${ }^{\circledR}$ ) instalada no local do experimento.

Três gramas de sementes de cebola da cultivar Empasc 352/Bola Precoce foram semeadas no canteiro em experimento constituído de blocos casualizados com oito repetições. Cada repetição apresentava uma área de 1,00 x 1,00 m, totalizando no mínimo de 600 plantas por repetição. Para avaliação da queima das pontas, dez plantas em cada parcela foram previamente escolhidas e demarcadas aleatoriamente. A calagem, adubação, tratos culturais seguiram as normas da cultura (18) e não se utilizou inseticidas devido a não ocorrência de insetos no período de avaliação.

Para que houvesse inóculo do patógeno na área, mudas de cebola com 30 dias de idade foram inoculadas com auxílio de um atomizador portátil uma suspensão $\left(10^{4}\right)$ de conídios de B. squamosa e após 24 horas de câmara úmida foram transplantadas a cada um metro linear ao redor do experimento no dia da semeadura. Também foram depositados cinco escleródios do patógeno produzidos pela técnica de Marcuzzo et al. (13) entre as parcelas, para também servir de inóculo primário da doença na área.

A coleta dos conídios de $B$. squamosa no ar foi realizada através de um coletor de esporos tipo "cata-vento" (20), posicionado a 0,4 metros de altura, localizado no centro do experimento. No interior do coletor havia uma lâmina de microscópio $(7,5$ x 2,5 cm) untada com vaselina a qual era substituída semanalmente. Em laboratório, a lâmina foi dividida em dois pontos centrais e adicionou-se 2 gotas de azul de metileno 33\% diluído em água foram depositadas lamínulas $(1,8 \times 1,8$ $\mathrm{cm}$ ) correspondendo a uma área de $6,48 \mathrm{~cm}^{2}$. Através da visualização em microscópio ótico com a objetiva de 10 vezes, quantificou-se o número de conídios coletados semanalmente.

A severidade da doença foi estimada semanalmente através da porcentagem de área foliar afetada pela doença em cada folha exposta (4).

Nas dez plantas avaliadas para a intensidade da doença determinouse a produtividade da biomassa fresca $(\mathrm{g})$ total, das folhas e raízes de cada muda.

Modelos não lineares, comumente usados para representar crescimento de epidemias como o Logístico e o de Gompertz foram usados para ajuste com os dados observados. Os critérios estabelecidos para comparação dos modelos, em função da qualidade do ajustamento dos dados foram: a) erro padrão da estimativa; b) estabilidade dos parâmetros; c) erro padrão dos resíduos; d) visualização da distribuição dos resíduos ao longo do tempo e e) pseudo $\mathrm{R}^{2}$.

$\mathrm{O}$ progresso da doença foi relacionado à variação da população de conídios no ar e comparada com as condições ambientais para a elaboração de uma fundamentação teórica da epidemiologia da queima das pontas das folhas da cebola.

\section{RESULTADOS E DISCUSSÃO}

Para estabelecer as relações entre o progresso de uma doença e as condições ambientais é necessário conhecer os fatores ambientais favoráveis ao desenvolvimento da doença (22). Durante o período de avaliação constatou-se que ocorreu na safra de 2017 uma precipitação pluvial de $485 \mathrm{~mm}, 183 \%$ a mais do que em 2018, na qual foram registrados $171 \mathrm{~mm}$ (Figura 1A). A precipitação tem uma relação direta com probabilidade de infecção do patógeno $(7,24)$. Isso fez com que o progresso da doença em ambos os anos fosse afetado (Figura 3), pois em 2017 foram mais distribuídas e isso também é dependente do inóculo do patógeno presente no ambiente, já que na $6^{\mathrm{a}}$ e $7^{\mathrm{a}}$ semana não foram coletados esporos em comparação a 2018 (Figura 2). Em decorrência disso, houve redução da infecção com reflexo no progresso, com pequeno incremento da $7^{\mathrm{a}}$ a $9^{\mathrm{a}}$ semana na safra 2017 (Figura 3). No entanto, apesar de incremento nos índices pluviais que ocorreram nos últimos 15 dias em 2018, a doença teve um acentuado progresso a partir da $8^{\circ}$ semana, isso, provavelmente, porque os conídios coletados anteriores a esse período (Figura 2) garantiram a infecção e, por isso, a chuva não influenciou diretamente no progresso da doença (Figura 3). Vicelli \& Lorbeer (23) utilizam a precipitação pluvial como um dos critérios de infecção de B. squamosa no sistema Bhight-alert desenvolvido no estado de Nova York nos Estados Unidos da América.

A temperatura média do ar foi de $15,8^{\circ} \mathrm{C}$ e $15,1^{\circ} \mathrm{C}$ respectivamente em r. 17 e 2018 no período de 10 semanas ( $1 \mathrm{~A}$ ), condição favorável ao desenvolvimento da doença (15), pois Carisse et al. (5) constataram que a faixa de 15 a $20^{\circ} \mathrm{C}$ foi as que ocorreu maior número de lesões por $\mathrm{cm}^{2}$. B. squamosa tem requerimentos térmicos amplos em cada fase do seu ciclo de vida, onde a produção de conídios é favorecida por temperaturas de 14 a $20^{\circ} \mathrm{C}(21)$, já a germinação dos conídios pode variar de 10 a $30^{\circ} \mathrm{C}(14)$ e para o desenvolvimento micelial de 15 a 20 ${ }^{\circ} \mathrm{C}$ (12). Temperaturas semelhantes foram registradas no período de avaliação, sendo que a média das máximas foi de 18,3 e $18,1{ }^{\circ} \mathrm{C}$ e a média da mínima em 13,3 e 12, $1^{\circ} \mathrm{C}$ respectivamente em 2017 e 2018.

Constatou-se que o período de duração da umidade relativa do ar acima dos $90 \%$, foi de 18 e 13,1 horas para 2017 e 2018 respectivamente (1B). A presença de umidade relativa alta é fundamental para o ciclo de vida do patógeno conforme constatado por Alderman \& Lacy (1). Esse valor acima de $90 \%$ de umidade relativa foi um critério usado utilizado por Vancelli \& Lorbeer (25) no desenvolvimento de um sistema de previsão, pois valores abaixo disso acabam resultando em condições desfavoráveis para a ocorrência da doença. No entanto Sutton et al. (21) considerou valores acima de $70 \%$ de umidade relativa para relacionar epidemias da doença. Independentemente das condições ambientais de cada fase do ciclo de vida do patógeno, as condições de umidade relativa do ar foram satisfatórias em ambos os anos de avaliação. $\mathrm{O}$ fato de ter encontrado altas horas de umidade relativa acima dos $90 \%$ (Figura 1B) é característica da região, pois é em um vale próximo a serra geral e resulta no acúmulo da umidade no ar.

O início da doença a partir da 6 e $7^{\mathrm{a}}$ semana respectivamente para 2017 e 2018, pode ser explicado por alguns fatores. Um deles pode ter sido as folhas mais velhas que apresentam menor cerosidade, resultando em maior retenção do molhamento propiciado pela chuva o que favorece a infecção. Outro aspecto evidenciado foi que a doença teve início em 2018 (Figura 3) uma semana antes da coleta de conídios 


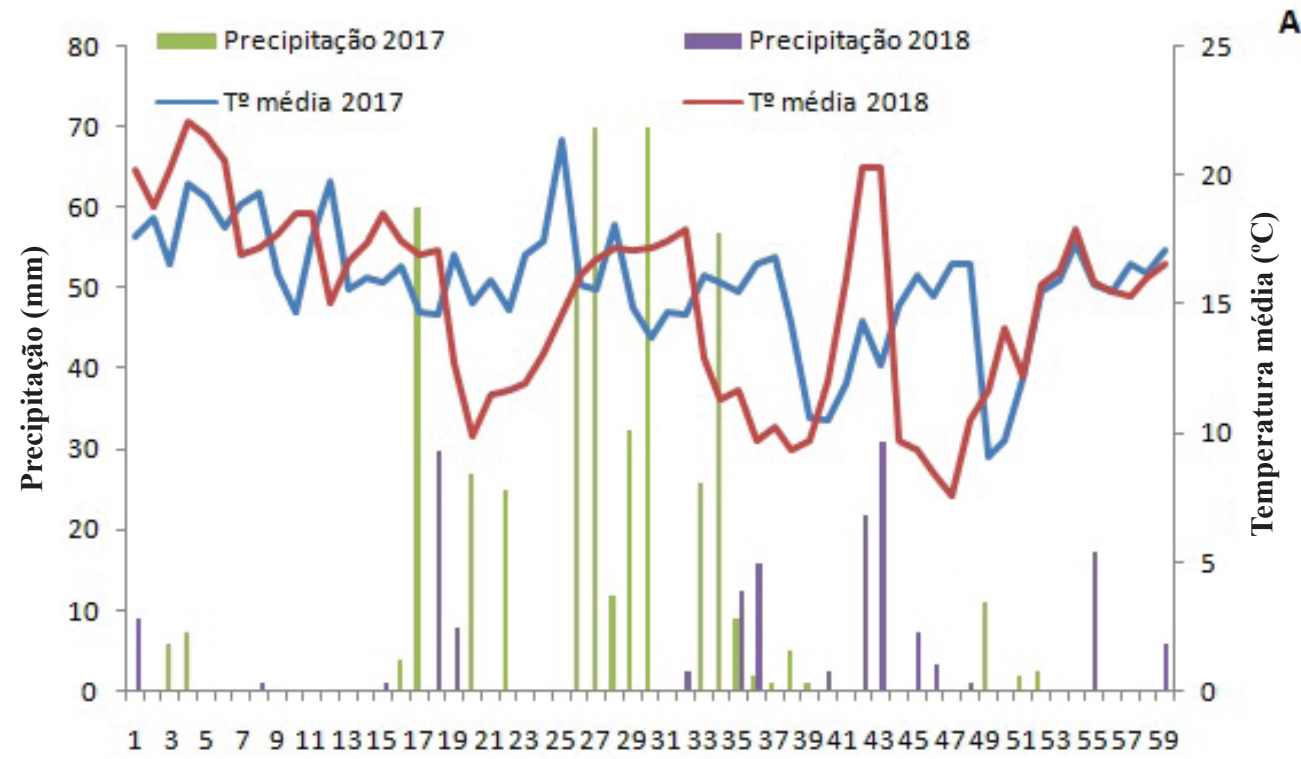

Dias após transplantio

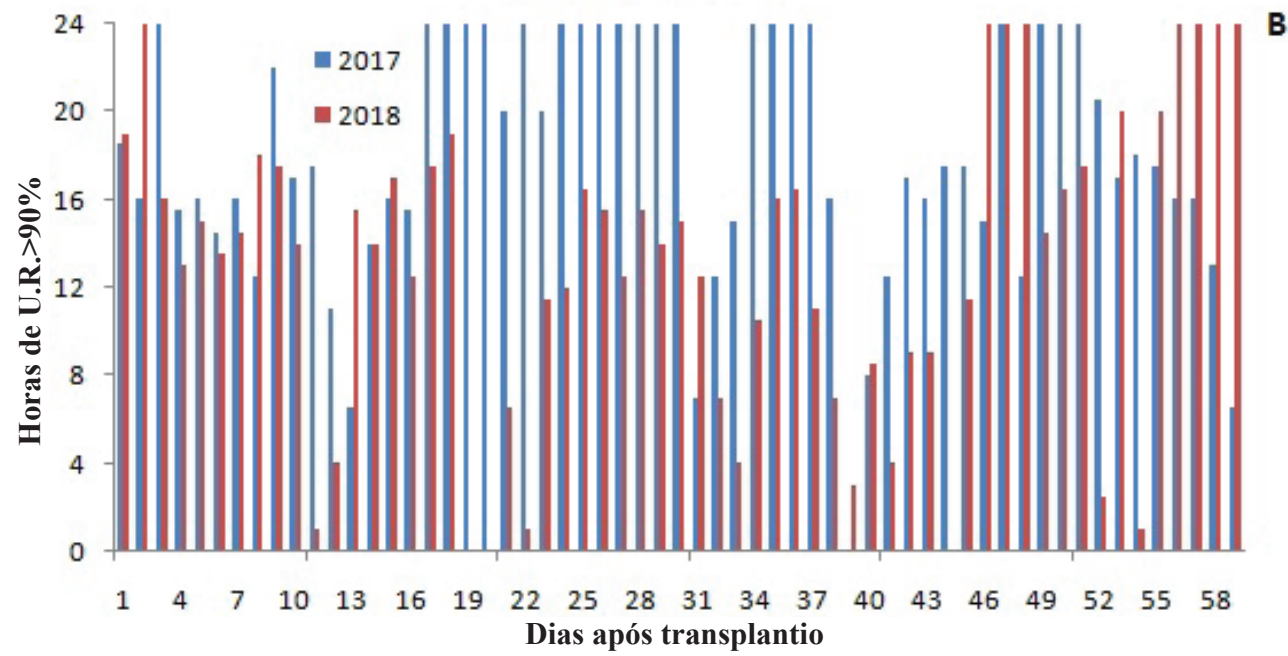

Figura 1. Flutuação da precipitação pluvial $(\mathrm{mm})$, da temperatura média do ar $\left({ }^{\circ} \mathrm{C}\right)(\mathrm{A})$ e da umidade relativa $\geq 90 \%$ (horas) (B) durante o período do estudo da queima das pontas das folhas da cebola. IFC/Campus Rio do Sul 2017 e 2018.

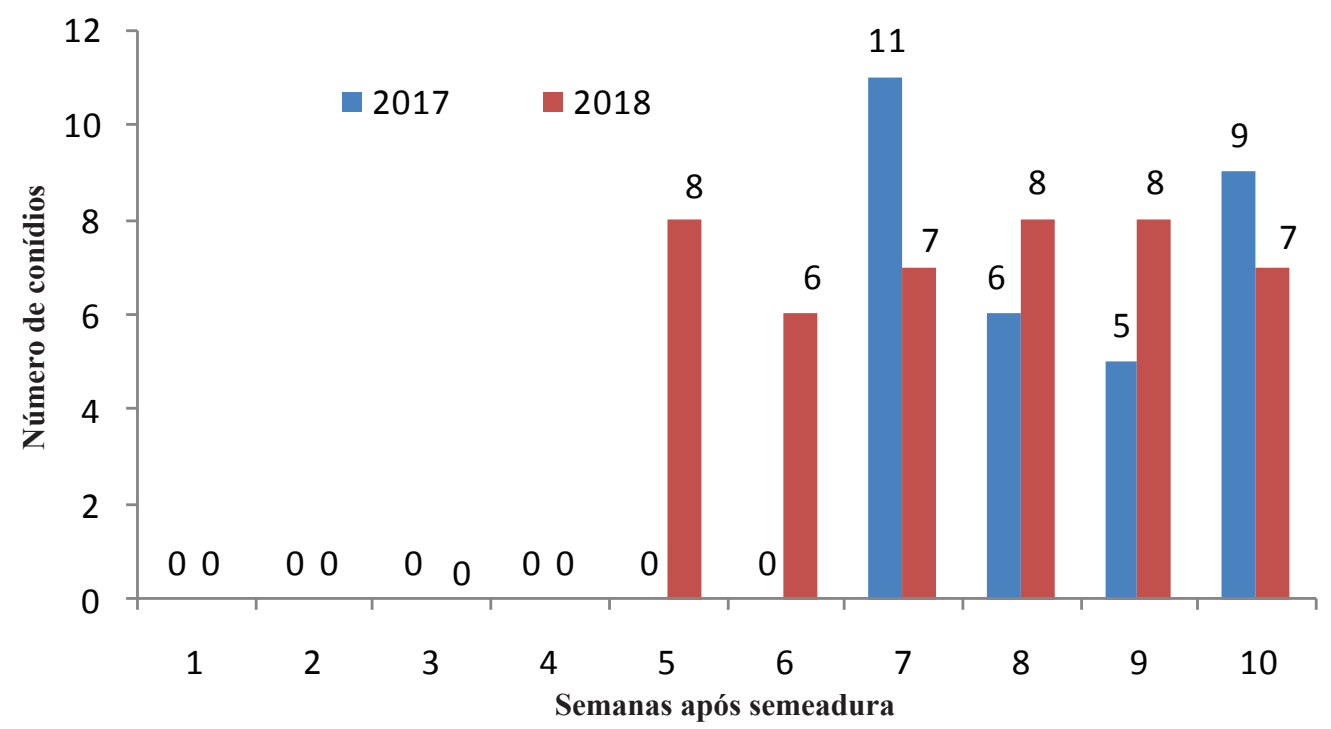

Figura 2. População de conídios coletados semanalmente após a semeadura durante a fase de mudas da cebola. IFC/Campus Rio do Sul 2017 e 2018. 


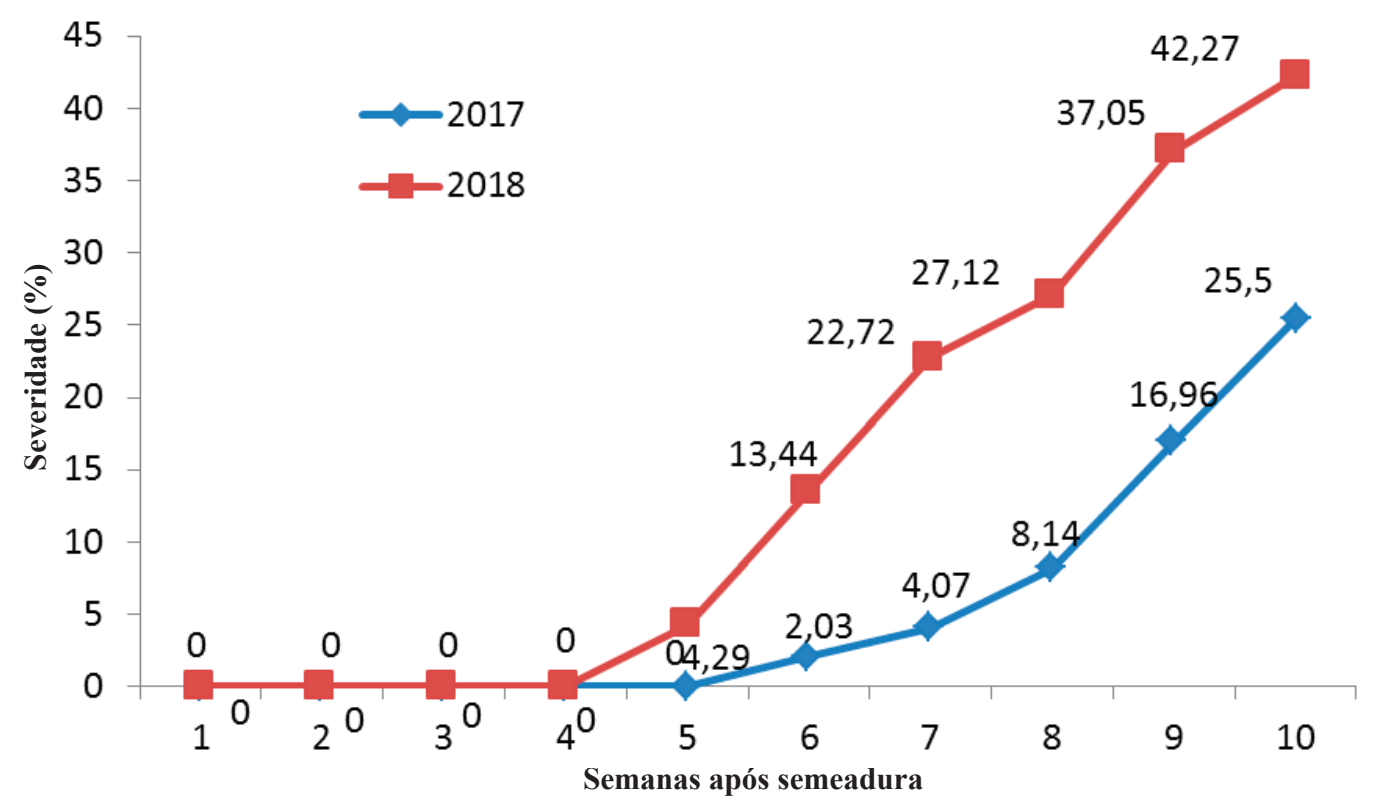

Figura 3. Severidade (\%) foliar observada da queima das pontas das folhas da cebola (Botrytis squamosa) em semanas após a semeadura durante a fase de mudas da cebola. IFC/Campus Rio do Sul 2017 e 2018.

no ar (Figura 2). Sutton et al. (21) também coletaram conídios de $B$. squamosa após ocorrer os sintomas, o que foi similar ao encontrado também com a ferrugem asiática da soja (10). À medida que aumenta a severidade da doença (Figura 3 ) ocorreu uma estabilização do número de conídios na 8 e $9^{\text {a }}$ semana em ambos os anos. Após a $9^{\text {a }}$ semana do início da doença em ambos os anos, observou-se um decréscimo dos conídios coletados principalmente em 2018, o que pode ser atribuído à baixa precipitação pluvial que ocorreu nas últimas semanas (Figura 1A). O menor número de conídios coletados ocorreu na última semana antes da colheita das mudas e isso pode ser associado ao fato de que as folhas primárias já se encontravam decompostas e o patógeno não se reproduzia mais nos tecidos necrosados (Figura 3) (26). A flutuação apresenta uma relação significativa entre a presença dos esporos no ar com o progresso da doença (16), pois isso foi verificado na flutuação de esporos de Monilinia fructicola (Wint) Honey coletados foi constante em armadilhas do tipo "cata-vento" durante o período vegetativo da cultura do pessegueiro (11), e com isso, evidenciando que o inóculo presente no ambiente serve de um indicativo para a ocorrência da doença (19).

Durante o período da $6^{\mathrm{a}}$ e $10^{\mathrm{a}}$ semana de finalização de desenvolvimento das mudas ocorreu à maior severidade da doença, para ambos os anos. Em 2017 esse período foi mais curto, crescendo de $2,03 \%$ para $25,5 \%$ em cinco semanas, enquanto que em 2018 a severidade aumentou de $4,29 \%$ para $42,27 \%$ num período de seis semanas (Figura 3). A severidade final de 21,2\% foi relatada por Boff et al. (4), predizendo que pode variar conforme o ano e das condições de epidemia. A epidemia foi melhor ajustada pelo modelo de Gompertz na safra de 2018, sendo descrita pela função $0,51830 *(\exp (-5,95660 * \exp (-$ $0,47392 * x))),\left(R^{2}=0,99916\right)$, onde a taxa $(0,47392)$ nas condições observadas, comprova o avanço da doença após a 6 a semana para ambos os anos (Figura 2). Duffeck \& Marcuzzo (6) avaliando uma epidemia da queima das pontas por B. squamosa em 2012 verificaram uma taxa de 0,58 , próximo ao encontrado no presente trabalho.

A biomassa fresca total produzida de cada muda foi de 1,68 e 2,70 gramas respectivamente nas safras de 2017 e 2018 , enquanto que a de folhas foi de 0,92 e 1,8 e de raízes de 0,76 e 1 grama em média de cada planta avaliada. Menezes Júnior et al. (17) obteve 5 gramas de biomassa fresca da parte área em sistema convencional de produção de mudas, evidenciando com isso a drástica redução de biomassa fresca da muda pela doença. A diferença de 60,71\% da biomassa fresca total em 2017 provavelmente se deve a um menor número de dias com luminosidade, já que em grande parte dos dias houve chuvas (Figura 1A) e/ou foram nublados, além da lixiviação dos nutrientes do solo pelo excesso hídrico.

Este estudo exploratório de alguns aspectos da epidemiologia contribuiu para estabelecer o momento do início e do progresso da doença com as condições ambientais, fatores que poderão ser úteis na validação de um sistema de previsão para a queima das pontas das folhas da cebola.

\section{AGRADECIMENTOS}

Os autores agradecem o apoio financeiro recebido do Conselho Nacional de Desenvolvimento Científico e Tecnológico - CNPq-Brasil nas bolsas de iniciação científica Pibiti e Pibic do Cnpq. Ao técnico de campo, Marcio Rampelotti pela implantação do experimento.

\section{REFERÊNCIAS}

1. Alderman, S.C.; Lacy, M.L. Influence of dew period and temperature on infection of onion leaves by dry conidia of Botrytis squamosa. Phytopathology, St. Paul, v.73, n.7, p.1020-1023, 1983.

2. Araújo, E.R.; Marcuzzo, L.L.; Alves, D.P. Manejo de doenças. In: Nick, C.; Borém, A. Cebola: do plantio a colheita. Viçosa: UFV, Cap.7, p.126$155,2018$.

3. Bergamim Filho, A.; Amorim, L. Doenças de plantas tropicais: epidemiologia e controle econômico. São Paulo: Ceres, 1996. 299 p.

4. Boff, P.; Gonçalves, P.A.S.; Debarba, J.F. Efeito de preparados caseiros no 
controle da queima-acizentada, na cultura da cebola. Horticultura brasileira, Brasília, DF, V.17, n.2, p.81-85, 1999.

5. Carisse, O.; Levasseur, A.; Van der Heyden, H. A new risk indicator for botrytis leaf blight of onion caussed by Botrytis squamosa baseado n infection efficiency of airbone inoculum. Plant pathology, Oxford, v.61, n.11, p.1154-1164, 2012.

6. Duffeck, M.R.; Marcuzzo, L.L. Progresso temporal da queima das pontas (Botrytis squamosa) em mudas de cebola na região do alto vale do Itajaí/ SC. Summa Phytopathologica, Botucatu, v.39, supl., 2013. (1 CD-ROM).

7. Duffeck, M.R.; Marcuzzo, L.L. Influência da precipitação pluvial sobre a severidade da queima das pontas (Botrytis squamosa) em canteiro de mudas de cebola. In: Dia de Pesquisa, Ensino, Produção e extensão - PEPE, 1., 2011, Rio do Sul. Anais. Rio do Sul: IFC, 2011. 1 CD-ROM.

8. IBGE. Levantamento sistemático da produção agrícola: pesquisa mensal de previsão e acompanhamento das safras agrícolas no ano civil, dezembro 2017. Rio de Janeiro, 2018 Disponível em:< https://biblioteca.ibge.gov. $\mathrm{br} /$ index.php/biblioteca-catalogo? view $=$ detalhes $\& \mathrm{id}=76>$. Acessoem: 04 jul. 2018

9. Jeger, M.J. Analysing epidemics in time and space. Plant Pathology, Oxford, v.32, n.1, p.5-11, 1983

10. Juliatti, F.C.; Rezende, A.A.; Vale, F.X.R. Critérios práticos de fundamento epidemiológico que auxiliam na tomada de decisão para o controle de doenças de plantas. Tropical Plant Pathology, Brasília, DF, v.35, supl., p.23-25, 2010. (resumo).

11. Keske, C. Epidemiologia da podridão parda em pessegueiros conduzidos em sistema de produção orgânico no alto vale do Itajaí - SC. 2009. 119f. Tese (Doutorado em Produção Vegetal) - Universidade Federal do Paraná, Curitiba.

12. Marcuzzo, L.L.; Souza, J.J. Efeito da temperatura e do fotoperíodo no desenvolvimento micelial de Botrytis squamosa, agente causal da queima das pontas da cebola. Summa phytopathologica, Botucatu, v.44, n.1, p.90-91, 2018.

13. Marcuzzo, L.L.; Nascimento, A.; Kotkoski, B. Technique for inducing Botrytis squamosa sclerotium formation in vitro. Summa phytopathologica, Botucatu, v.43, n.3, p.251, 2017.

14. Marcuzzo, L.L.; Eli, K. Effect of temperature and photoperiod on the in vitro germination of conida of Botrytis squamosa, the causal agent of Botrytis leaf blight of onion. Summa phytopathologica, Botucatu, v.42, n.3, p.261-263, 2016.
15. Marcuzzo, L.L.; Haveroth, R. Development of a weather-based model for Botrytis leaf blight of onion. Summa phytopathologica, Botucatu, v.42, n.1, p.92-93, 2016

16. Marcuzzo, L.L.; Duffeck, M.R. Flutuação populacional de esporângios de Peronospora destructor no ar e sua relação com severidade do míldio da cebola. Summa Phytopathologica, Botucatu, v.41, n.1, p.68-70, 2015.

17. Menezes Júnior, F.O.G.; Gonnçalves, P.A.; Vieira Neto, J. Produtividade, incidência de tripés e perdas pós-colheita da cebola sob adubação orgânica e uso de biofertilizantes. Revista de ciências agroveterinárias, Lages, v.12, n.3, p.264-270, 2013.

18. Menezes Júnior, F.O.G; Marcuzzo, L.L. Manual de boas práticas agrícolas: sustentabilidade das lavouras de cebola do estado de Santa Catarina. Florianópolis: Epagri, 2016, 143p.

19. Reis, E.M.; Mário, J.L. Quantificação do inóculo de Diplodia macrospora e de $D$. maydis em restos culturais, no ar, e sua relação com a infecção em grãos de milho. Fitopatologia Brasileira, Brasília, DF, v.28, n.2, p.143147, 2003.

20. Reis, E.M.; Santos, H.P. População de Helmintosporium sativum no ar quantificado através de uma armadilha tipo cata-vento. Fitopatologia Brasileira, Brasília, DF, v.10, n.5, p.515-519. 1985.

21. Sutton, J.C.; Swanton, C.J.; Gillespie, T.J. Relation of weather variables and host factors to incidence of airborne spores of Botrytis squamosa. Canadian Journal Botany, Otawa, v.56, n.20, p.2460-2469, 1978.

22. Vale, F.X.R.; Zambolim, L. Influência da temperatura e da umidade nas epidemias de doenças de plantas. Revisão Anual de Patologia de Plantas, Passo Fundo, v.4, p.149-207, 1996.

23. Vincelli, P.C.; Lorbeer, J.W. BLIGTH-ALERT: A weather-based predictive system for timing fungicide applications on onion before infection periods of Botryts squamosa. Phytopathology, St. Paul, v.79, n.4, p.493-498, 1989.

24. Vincelli, P.C.; Lorbeer, J.W. Relationship of precipitation probability to infection potencial of Botrytis squamosa on onion. Phytopathology, St. Paul, v.78, n.8, p.1078-1082, 1988.

25. Vincelli, P.C.; Lorbeer, J.W. Forecasting spore episodes of Botrytis squamosa in commercial onion fields in New York. Phytopathology, St. Paul, v.78, n.7, p.966-970, 1988.

26. Wordell Filho, J. A.; Boff, P. Queima-acizentada - Botrytis squamosa Walker. In: Wordell Filho, J.A.; Rowe, E.; Gonçalves, P.A.; Debarba, J.F.; Boff, P.; Thomazelli, L.F.. Manejo Fitossanitário na cultura da cebola. Florianópolis: EPAGRI, p.19-30, 2006. 